\title{
Acoustic, kinematic and aerodynamic aspects of word- initial and word-final vowels in pre-boundary context in French
}

\section{Cédric Gendrot}

LPP (Laboratoire de Phonétique et de Phonologie). Université Paris3 Sorbonne Nouvelle - ILPGA, France. CNRS UMR 7018.

Four speakers repeated 8 times 15 sentences containing ' $p V p$ ' syllables ( $\mathrm{V}$ being /a/, /i/ and /u/). The 'pVp' syllables were located in final, penultimate and antepenultimate position relatively to the Intonational Phrase (IP) boundary. They were embedded in lexical words of 1-3 syllables and were either word-initial or word-final. Results show that the closer the vowel in word-final position is to the IP boundary, the longer the duration and the higher the fundamental frequency of the vowel; it is also characterised by larger lip opening gestures. The potential reduction or coarticulation of vowels in wordinitial position compared to their counterparts in word-final position is discussed.

\section{Introduction}

\subsection{Articulatory prosody}

This study is located within the field of articulatory prosody, i.e. the influence of prosody on the articulation of speech sounds. In this framework the most obvious variations are linked to the boundaries (at the edges of prosodic domains, in the immediately preceding and following context) and to prominences in numerous languages. Segments around the boundaries and in prominent position are characterised by a strengthening of their articulatory properties (Fougeron 1998, Keating et al. 2003, Cho 2001). The term 'strengthening' may be defined here as an increase of spatial and temporal dimensions, such as for example consonants will be articulated with more extreme and longer constrictions; vowels will be articulated reaching their 
respective targets and staying there for a longer duration. This prosodically conditioned strengthening is usually considered as linguistically significant, insofar as it can lead to increased linguistic contrast between segments. This is true on a syntagmatic scale (increased contrast between neighbouring segments) as well as on a paradigmatic scale (increased difference between contrastive phonemes in the language sound system). For example more jaw opening for enhancing the vocalic character of a vowel may generate a louder sound, thus making it more distinct from the surrounding consonants. This can also be true for closed vowels such as /i/ and /u/ (Erickson 1998, Harrington et al 2000). In the latter study, the authors reported a possible conflict and argued that a higher and fronter tongue position for /i/ gave support for a more peripheral vowel in its articulatory and acoustic aspects, while a lower jaw position gave support for the increased sonority hypothesis (cf. section 1.4 for a quick presentation of both hypotheses).

\subsection{Prosody in French}

In French, a word or a group of words which constitute a 'meaning unit' or "groupe de sens" (Grammont 1933) tend to form a single acoustic unit and the last syllable of the meaning unit carry a so-called final, primary or logical accent. This group accent has a demarcative function, namely it signals the end of a group and is thus correlated with the occurrence of a boundary.

The first prosodic position we will deal with here is the major boundary in French: the so-called "continuation majeure" in Delattre's terms (1966). In read isolated sentences, it is usually found at the juncture between the Noun Phrase (NP) and the Verb Phrase (VP) (cf. Fig. 1). The "continuation majeure" is acoustically cued by a continuation rise ( $\mathrm{H} \%$ in French ToBI notation by Jun \& Fougeron (1997)), and by an extra lengthening of the last syllable before the juncture, as compared to the other sense-groups in the sentence.

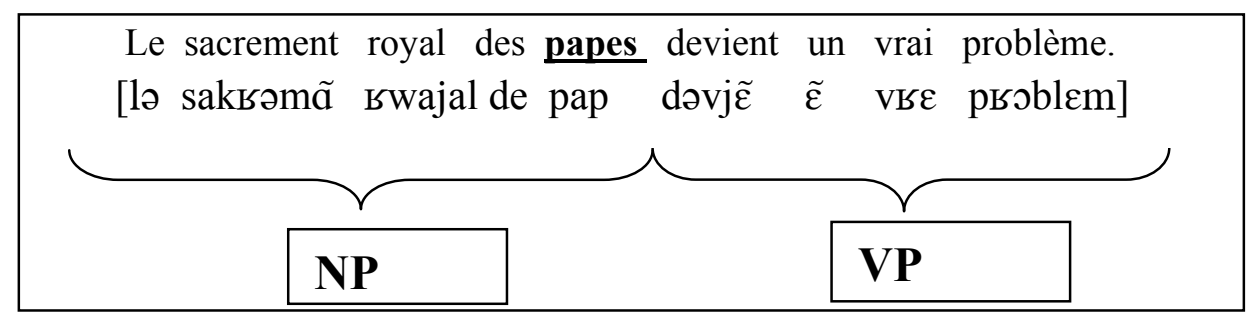

Figure 1: Example of major boundary occurring after the lexical word 'papes' [pap]. Translation: Royal sacrament of popes is becoming a real problem. 
It is also hypothesised to be realised with greater articulatory gestures: consonants are being produced with a stronger closing gesture and vowels with a greater opening (Straka 1963).

The second position of interest in this work is the word initial position in French. It may be a specific position for what is called the "word initial accent". The word initial accent's most puzzling characteristic is its optional realisation as its presence and its exact position may be conditioned by different factors such as rhythm (Pasdeloup 1990), speaker identity (Vaissière 1975) or style (Vaissière 1975, Lucci 1983). It is acoustically signalled by a f0 rise, which is timed with the very beginning of the word, but may end on one of the first syllables, generally the first or the second. We will globally consider the word initial position in this study, for which no study has yet provided an articulatory description in French.

\subsection{The $\pi$-gesture activity}

Byrd and colleagues (Byrd et al. 2000, Saltzman \& Byrd 2000b, Byrd \& Saltzman 2003), after Beckman, Edwards and colleagues (1992), introduced the $\pi$-gesture (prosodic-gesture) into the Articulatory Phonology framework.

"We expand on this concept [Articulatory Phonology] by proposing that prosodic (non-constriction-based) gestures also exist, occuring at domain edges. We refer to such prosodic boundary gestures as $\pi$ gestures. Like articulatory gestures, $\pi$-gestures have an inherent temporal extent. These $\pi$-gestures are hypothesised to cause slowing at phrase edges by affecting the ongoing stiffness parameter values of all constriction gestures that are active within the $\pi$-gesture's activation interval. Stronger $\pi$-gestures slow the local speaking rate more (i.e. lower stiffness more) than weaker $\pi$-gestures. The prosodic boundary strength defines the activation level of a $\pi$-gesture." (Byrd 2000: 13).

These $\pi$-gestures will alter constriction gestures during a temporal interval which varies according to the boundary strength. Its activation effect is also determined by boundary strength. According to this model articulatory gestures are slowed down - and possibly enlarged due to less overlapping according to their simulations (Byrd \& Saltzman 2003) - when in close contact to a boundary, and this slowing effect is attenuated when going further from this boundary. The consequence of such a model, allowing to rely upon dynamic prosody and aspects of articulatory gestures, has not been tested for French as far as we 
know, and the hypothesised slowing and enlarging of articulatory gestures will be tested in this work in pre-boundary context.

\subsection{Hypothesis}

Our hypothesis is that the closest vowels to the boundary in word-final position will be realised with longer and larger gestures compared to their counterparts further away from the boundaries in word-initial position. Thus we will consider the span of the activation of the $\pi$-gesture, or more generally if the results are coherent with the $\pi$-gesture hypothesis.

Our aim is to characterise the strengthening hypothesised to occur on the last syllable in immediate pre-boundary context (Tabain 2003a,b). Indeed the closest the vowel is to the boundary, the most strengthened it should be, compared to the same vowel further away from the boundary. Two hypotheses concerning the nature of the strengthening are found in the literature:

- Sonority Expansion Hypothesis: Edwards \& Beckman (1988), Beckman \& Edwards (1992) following Straka's hypothesis (1963) state that

" the lengthening associated with accented sequence, on the other hand, is a head effect. [...] That is, the purpose of the lengthening seems to be not to make the sequence longer per se, but rather to expand the portion of the syllable where maximum energy is radiating out of the mouth." (Beckman \& Edwards, 1992: 369).

They predict that the opening contrast between the accented vowel and the following consonant is maximised, thus participating in a greater syntagmatic highlighting of the syllabic nucleus under accent.

- De Jong (1995) proposes a slightly different hypothesis according to which the distinctive features of vowels should be increased, allowing a paradigmatic contrast relying on phonemic distinction between segments occurring on a same syntagmatic position or between lexical units. This hypothesis is inspired by the works of Lindblom (1990), relying more specifically on hyper-articulation of syllables. 


\section{Method}

\subsection{Measurements}

A set of experimental methods simultaneously recorded (cf. figure 2) will be used in order to allow us to evaluate the activity of the vocal apparatus at different levels:

- The sub-glottic effort. Subglottal Pressure (Ps) tends to be constant along the sentences, but Ps increase has been observed in sentence stress/emphasised syllables (Ladefoged 1958, Benguerel 1970). While direct Ps measurement is invasive, intra-oral pressure (PIO) is a non invasive method used to estimate the mean subglottal pressure for a vowel for adjacent unvoiced stop sounds alternating with vowel phonations (Hertegard 1995). The method is based on the fact that the pressure is equalised below and above the glottis during the closure period of unvoiced stop consonants when vocal folds are abducted. The closed syllable ' $p V p$ ' is used in our study with the assumption that there will not be much change in Ps between the vowel and the surrounding consonants. These data were collected with the FJ-electronics Aerophone II device at $1 \mathrm{KHz}$ and then resampled at $25 \mathrm{KHz}$.

- The glottic activity. f0 was measured from Electro-Glotto-Graphy (EGG) signal using a Laryngograph Ltd. In modal voice register, an increase of f0 mainly corresponds to an increase in crico-thyroid and thyro-arytenoid activity. The EGG as well as the acoustic signal was collected with DIANA physiological station at $25 \mathrm{KHz}$.

- The supraglottic articulators. From video-camera recordings (Digital Camera Canon XM2 at 34 frames/second). The lip aperture is measured manually using Matlab. Lip aperture movement is measured as the maximum amplitude of opening between the maximally closed position of the first $/ \mathrm{p} /$ and the maximally closed position of the second /p/ (e.g. ,pap“).

Data curves were obtained from these measurements. These curves were first synchronised to the acoustic signal using a second acoustic signal from the camera and then up-sampled at $25 \mathrm{KHz}$.

- Acoustic measurements (F1 and F2 formant analysis, duration) completed the different physiological values recorded for this corpus. A manual segmentation was realised so as to measure the duration of analysed vowels. Praat scripts were used to get these acoustic values (Gendrot \& Adda 2004). Formant values were systematically checked however as closed vowels such as $/ \mathrm{u} /$ and $/ \mathrm{i} /$ are sometimes partly unvoiced and thus more difficult to analyse. Moreover the first 
two formants of $/ \mathrm{u} /$ being close to each other can bring some difficulties for automatic formant detection systems.

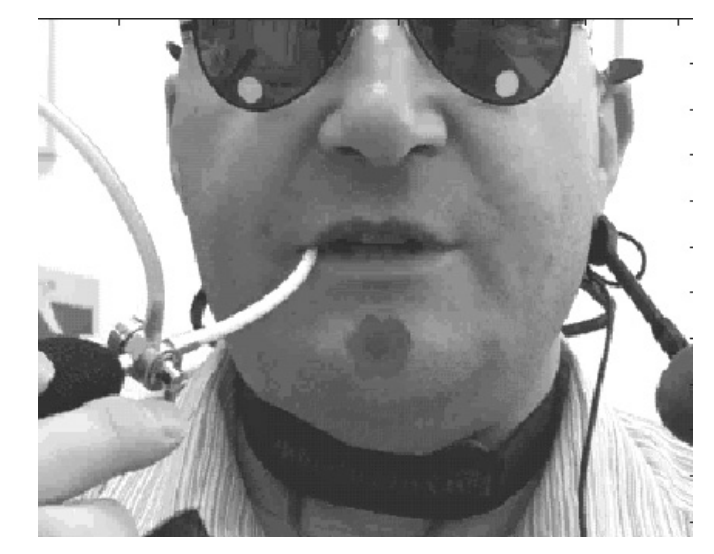

Figure 2: Example of speaker M1 with multiple device (EGG, intra-oral pressure, video, microphone)

\subsection{Corpus and data collection}

The vowels $(/ \mathrm{a} /, / \mathrm{i} /$ and $/ \mathrm{u} /)$ were embedded in a 'pVp' syllable context. Each syllable was tested in 5 different contexts (thus 5 different sentences) developed below. The heading we shall use afterwards to refer to these conditions is given between square brackets:

1. last syllable of a lexical word in a pre boundary context [word final]

a. monosyllabic word [1syll_fin]

b. bisyllabic word [2syll_fin]

2. first syllable of a lexical word in pre-boundary context [word initial]

a. bisyllabic word [2syll_ini]

b. trisyllabic word [3syll_ini]

3. last syllable of a bisyllabic lexical word followed by a monosyllabic word in a pre-boundary context. The first lexical word (soupapes neuves) should still be characterised by word lengthening.

In short there were altogether 3 vowels $* 5$ different sentences (conditions) $=15$ sentences each repeated 8 times during the recording. 
Table 1: Sentences used in the corpus for vowel /a/. Studied syllables are in bold and underlined ; $\sigma$ : syllables ; [ ]: word ; \#: boundary

\begin{tabular}{|l|l|l|}
\hline $1 \mathrm{a}$ & {$[\underline{\sigma}] \#$} & $\begin{array}{l}\text { Le sacrement royal des papes [pap] devient un vrai problème. } \\
\text { Royal sacrament of popes is becoming a real problem. }\end{array}$ \\
\hline $1 \mathrm{~b}$ & {$[\sigma \underline{\sigma}] \#$} & $\begin{array}{l}\text { La mise en rayon des soupapes [supap] devrait vite s'arrêter. } \\
\text { The shelving of valves should stop soon. }\end{array}$ \\
\hline $2 \mathrm{a}$ & {$[\underline{\sigma} \sigma] \#$} & $\begin{array}{l}\text { La dernière collection des paperasses [papsas] a lieu le } 20 \text { juin. } \\
\text { The last collection of papers will take place on june the } 20^{\text {th }} .\end{array}$ \\
\hline $2 \mathrm{~b}$ & {$[\underline{\sigma} \sigma \sigma] \#$} & $\begin{array}{l}\text { La mise en hypothèque des paperasseries [papsasbi] m'énerve } \\
\text { beaucoup. } \\
\text { The mortgage of paperwork makes me really angry. }\end{array}$ \\
\hline 3 & {$[\sigma \underline{\sigma}][\sigma] \#$} & $\begin{array}{l}\text { La mise en rayon des soupapes neuves [supapnœv] devrait vite finir. } \\
\text { The shelving of new valves should stop soon. }\end{array}$ \\
\hline
\end{tabular}

The last condition (3) is considered as the reference. The examples were chosen so as to make sure the two words could be said in a straight way by the speakers. The syllable [pap] is then located before a word boundary and should undergo word final lengthening, although fairly small as compared to that of higher boundaries (Di Cristo 1998 and references within).

According to our hypothesis, the vowels in condition $1 \mathrm{a}$ and $1 \mathrm{~b}$ should be more strengthened than in condition $2 \mathrm{a}$ and $2 \mathrm{~b}$ respectively. Both vowels in condition 3 and condition 2a are one syllable away from the boundary and in this regard could show similar results. However the tendency for word final lengthening in French could explain longer vowel duration (together with other differences) in condition 3 compared to $2 \mathrm{a}$.

\subsection{Procedure}

Four speakers were recorded in a quiet room of HEGP's hospital, 2 male speakers: M1 (39 years-old) and M2 (30 years-old); 2 female speakers: F1 (26 years-old) and F2 (25 years-old).

All of them have linguistic knowledge and have no identifiable accent. The author was conscious that utterances realised by our different speakers would not necessarily be representative of the desired prosodic conditions, i.e. Intonational Phrase (IP) boundaries. The author who guided the recording sessions made sure that the sentences in the corpus were not read too fast, but did not in any way induced the speaker to produce the expected realisations.

Following the same methodology, word initial positions could be realised as word initial accents according to the speaker's will (cf. section 1.2). The word initial accents were selected according to f0 values that were significantly higher than each speaker's mean values in the same condition. These outliers (23 
altogether) were discarded from further analysis. The reference condition (e.g. "soupapes neuves") could also be differently realised according to the speaker's will. The author made sure that no explicit pause would occur between the two lexical words during the experiment. In that case the speakers were asked to repeat after the explanation that a pause in this location would be unnatural.

\section{Data analysis}

\subsection{Duration}

Syllables in final position were expected to be longer than syllables in non-final position. A longer duration of the monosyllabic (condition 1a) as compared to the disyllabic (condition 1b) was also expected: the longer the words, the shorter the syllables should be (Nooteboom 1997).

Table 2: ANOVAs ${ }^{1}$ results for f0 and duration values for each speaker and vowel according to the condition factor.

\begin{tabular}{|c|c|c|c|c|c|c|}
\hline & $\mathrm{A}$ & & I & & $\mathrm{u}$ & \\
\hline $\begin{array}{l}\text { All Subjects } \\
\text { duration } \\
\text { f0 }\end{array}$ & $\begin{aligned} \mathrm{F}(4,141) & =7.422 \\
\mathrm{~F}(4,134) & =2.69\end{aligned}$ & $\begin{array}{l}* * \\
*\end{array}$ & $\begin{array}{l}\mathrm{F}(4,148)=5.35 \\
\mathrm{~F}(4,145)=3.14\end{array}$ & * & $\begin{array}{l}\mathrm{F}(4,158)=4.67 \\
\mathrm{~F}(4,154)=5.95\end{array}$ & * \\
\hline $\begin{array}{c}\text { Subject M1 } \\
\text { duration } \\
\text { f0 }\end{array}$ & $\begin{array}{l}F(4,33)=21.942 \\
F(4,26)=57.57\end{array}$ & $\begin{array}{l}* * \\
* *\end{array}$ & $\begin{array}{l}\mathrm{F}(4,35)=13.59 \\
\mathrm{~F}(4,35)=50.52\end{array}$ & $\begin{array}{l}* * \\
* *\end{array}$ & $\begin{array}{l}\mathrm{F}(4,34)=20.4 \\
\mathrm{~F}(4,34)=45.76\end{array}$ & $\begin{array}{l}* * \\
* *\end{array}$ \\
\hline $\begin{array}{r}\text { Subject M2 } \\
\text { duration } \\
\text { f0 } \\
\end{array}$ & $\begin{array}{c}F(4,30)=7.26 \\
F(4,30)=13.85\end{array}$ & $\begin{array}{c}* \\
* * \\
\end{array}$ & $\begin{array}{l}F(4,29)=1.07 \\
F(4,29)=4.68\end{array}$ & - & $\begin{array}{c}F(4,31)=3.3 \\
F(4,31)=47.52\end{array}$ & $\begin{array}{c}* \\
* * \\
\end{array}$ \\
\hline $\begin{array}{r}\text { Subject F1 } \\
\text { duration } \\
\\
\text { f0 }\end{array}$ & $\begin{array}{l}\mathrm{F}(4,32)=0.47 \\
\mathrm{~F}(4,32)=3.695\end{array}$ & - & $\begin{array}{c}\mathrm{F}(4,35)=3.2 \\
\mathrm{~F}(4,32)=10.82\end{array}$ & $\begin{array}{l}* \\
* *\end{array}$ & $\begin{array}{c}F(4,45)=2.56 \\
F(4,41)=32.1\end{array}$ & $\begin{array}{l}- \\
* *\end{array}$ \\
\hline $\begin{array}{r}\text { Subject F2 } \\
\text { duree } \\
\text { f0 }\end{array}$ & $\begin{array}{c}F(4,31)=4.4 \\
F(4,31)=15.6\end{array}$ & $\begin{array}{l}* \\
* *\end{array}$ & $\begin{array}{r}F(4,34)=6.76 \\
F(4,34)=40.42\end{array}$ & $\begin{array}{l}* \\
* *\end{array}$ & $\begin{array}{c}F(4,33)=1.81 \\
F(4,33)=26.86\end{array}$ & * \\
\hline
\end{tabular}

\footnotetext{
${ }^{1}$ The statistical package used was StatView 5.0.
} 


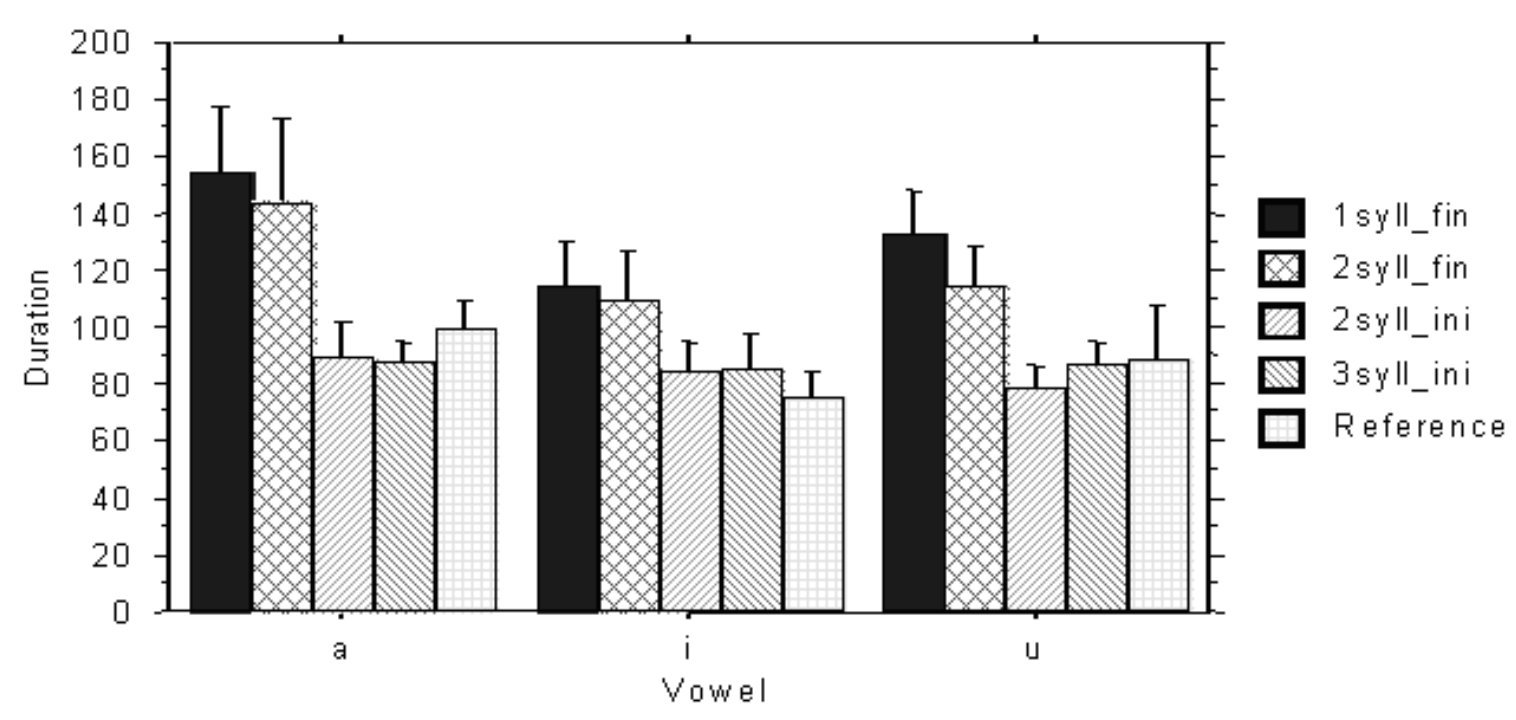

Figure 3: Duration values for $/ \mathrm{a} /, \mathrm{i} / \mathrm{and} / \mathrm{u} /$ for speaker M1. The five columns of each set are from left to right: 1_syll_fin, 2_syll_fin, 2_syll_ini, 3_syll_ini, reference.

The results show that the effect of condition is significant on vowel duration in most cases (except for speaker $\mathrm{F} 1$ on /a/ and /u/ for example: cf. table 2). As can be seen on figure 3, the values can be separated in two main groups: vowels in word final syllables are significantly longer than vowels in word initial syllables and in the reference condition. This is consistent with the boundary adjacent vocalic lengthening that is often mentioned in the literature (Delattre 1966).

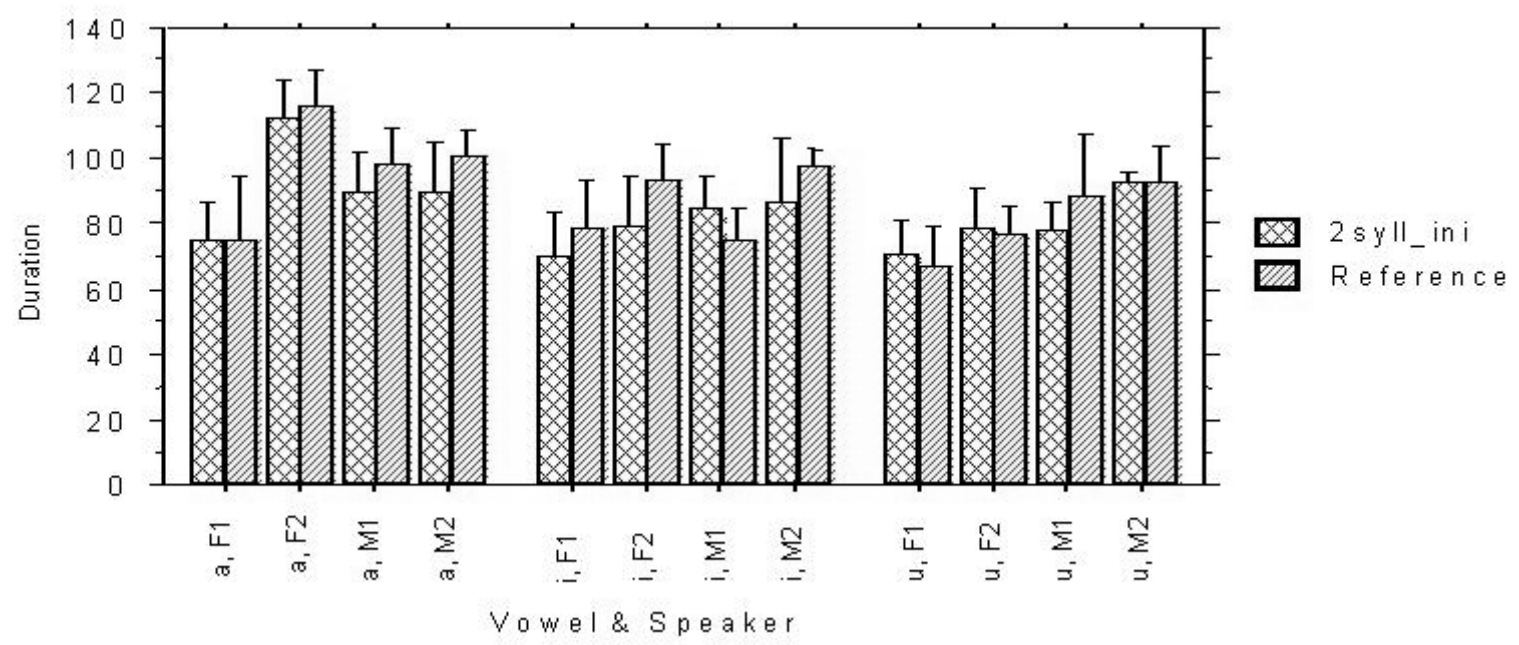

Figure 4: Duration values for $/ \mathrm{a} /, / \mathrm{i} /$ and $/ \mathrm{u} /$ for each speaker, comparing 2syll_ini and the reference conditions.

The results for the reference condition (soupapes neuves) show no significantly different values compared to condition $2 \mathrm{a}$ ( $\mathrm{p}=0.067$ given by the Fisher's PLSD 
Test), although the mean durations are usually slightly longer for the reference condition (the difference is significant for speaker M1 on /i/ and / $\mathrm{u} /$ only, as can be seen on figure 4 ). This is coherent with the $\pi$-gesture hypothesis, as the presence of the word boundary (reference condition) generally does not significantly lengthen the vowel.

\section{2. $f 0$}

Next we turn to a comparison of f0 values in word initial and word final position. The ANOVAs show that speakers significantly produce increased values of $\mathrm{f0}$ for the vowels in final syllables (1syll_fin and 2syll_fin) compared to their counterparts in word initial syllables. This is consistent with the boundary adjacent $\mathrm{f} 0$ continuation rise $(\mathrm{H} \%)$ that is often mentioned in the literature.

The only exception noticed is for vowel /a/ for speaker F1. Although the ANOVA shows a significant effect of condition on the f0 values, no tendency consistent with the other results can be found. This is similar to the results we found in the previous part for this speaker. As an increase in duration and $\mathrm{f} 0$ are useful indicators of boundary realisation, it suggests that speaker F1 did not realise the boundaries as intended (on sentences with /a/). As for sentences with vowel $/ \mathrm{u} /$ (cf. table 3: no significant effect of duration), the significant increase in $\mathrm{f} 0$ on the last syllable before the boundary suggests that speaker F1 realises boundaries by a continuation rise only (and not accompanied by a lengthening). We decided not to get rid of this speaker for further analyses as the kinematic analyses (lip aperture) could bring interesting results. Will the kinematic results be strictly coherent with the acoustic results observed ( $\mathrm{f0}$ and duration)?

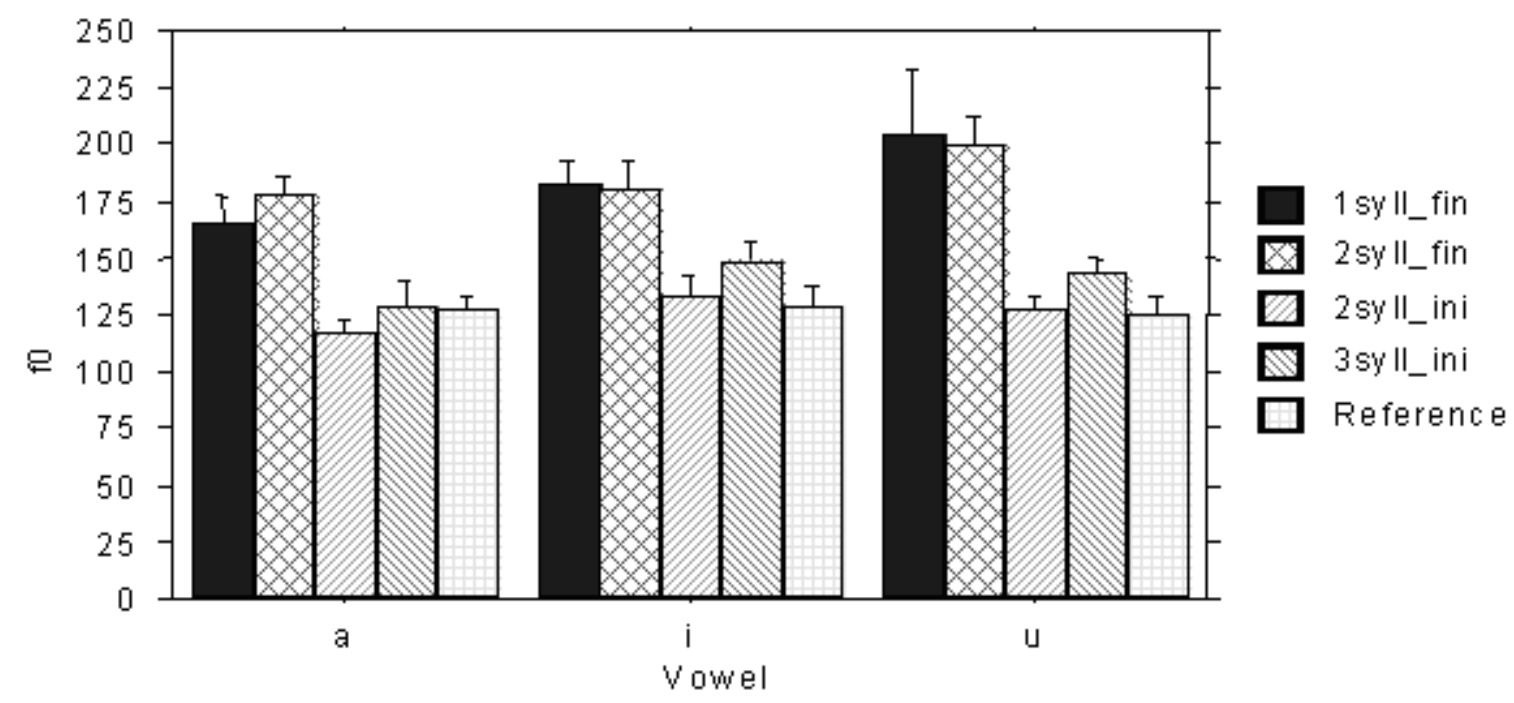

Figure 5: f0 values for /a/, /i/ and /u/ for speaker M1. 


\subsection{Formants}

Vowels in word final syllables (1_syll_fin and 2_syll_fin) were hypothesised to be more extreme in terms of a higher F1 when located in pre-Intonational Phrase boundary (as found by Tabain 2003a). This may be due to hyper-articulation and/or to longer duration. Vowels extracted from a large database (2 hours for French and for German) have shown to have more extreme values in terms of higher F1 and F2 with increasing duration (Gendrot \& Adda 2004). However, as for /a/, results for F2 are less systematic and obvious as noted by both studies. This result can be explained by the fact that) /a/ in French is rather central on the frontness-backness scale. If we consider the Sonority Expansion, F1 values would be systematically higher when close to a boundary, while no explicit hypothesis can be drawn for F2. If we refer to coarticulation, then vowels close to a boundary would be less coarticulated and thus have a higher F2 (a coarticulation effect would make F2 transition point towards a locus at approximately $600 \mathrm{~Hz}$; Delattre et al. 1955).

Target vowels $/ \mathrm{i} /$ and $/ \mathrm{u} /$ produced by speaker F1 were often devoiced and we were not able to investigate any results for this speaker. F1 and F2 values for /i/ and / $\mathrm{u} /$ were not significantly different according to 2 factor (,condition“ and "vowel") ANOVAs. We assume that this is due to a lack of variability of these extreme vowels as these are known to be less variable than /a/ (for example Recasens 1999). However, considering /a/, the effect of condition is significant for F1 and F2 values for all speakers. There is an overall tendency for vowels in word final syllables to have higher F1 values than vowels in word initial syllables. For speakers M1 and F1, vowels in condition 2b (3syll_ini) have significantly lower F1 values than vowels in final position (conditions 1a and $1 b)$. For the 2 others speakers, vowels in condition 2a (2syll ini) have significantly lower F1 values than vowels in final position. The $\overline{1}^{\text {st }}$ formant values for the reference condition are also significantly lower (except for speaker F2).

As for F2 values, the results follow the same trends as F1, but are significantly different for speaker M1 and M2 only. When considering that F1 is related to aperture and F2 to anteriority of the vowel, the results indicate that /a/ is more posterior and closed for vowels in word-initial syllables (cf. figure 7). This is interpreted here as a higher coarticulation, rather than more centralisation, as more centralisation would lead F2 to move towards $1500 \mathrm{~Hz}$ instead of lowering, as can be noticed here. The $2^{\text {nd }}$ formant values for the reference condition are slightly higher than vowels in word initial position (for both speakers M1 and M2, not shown in the figure), which suggests that they are rather centralised than coarticulated. 


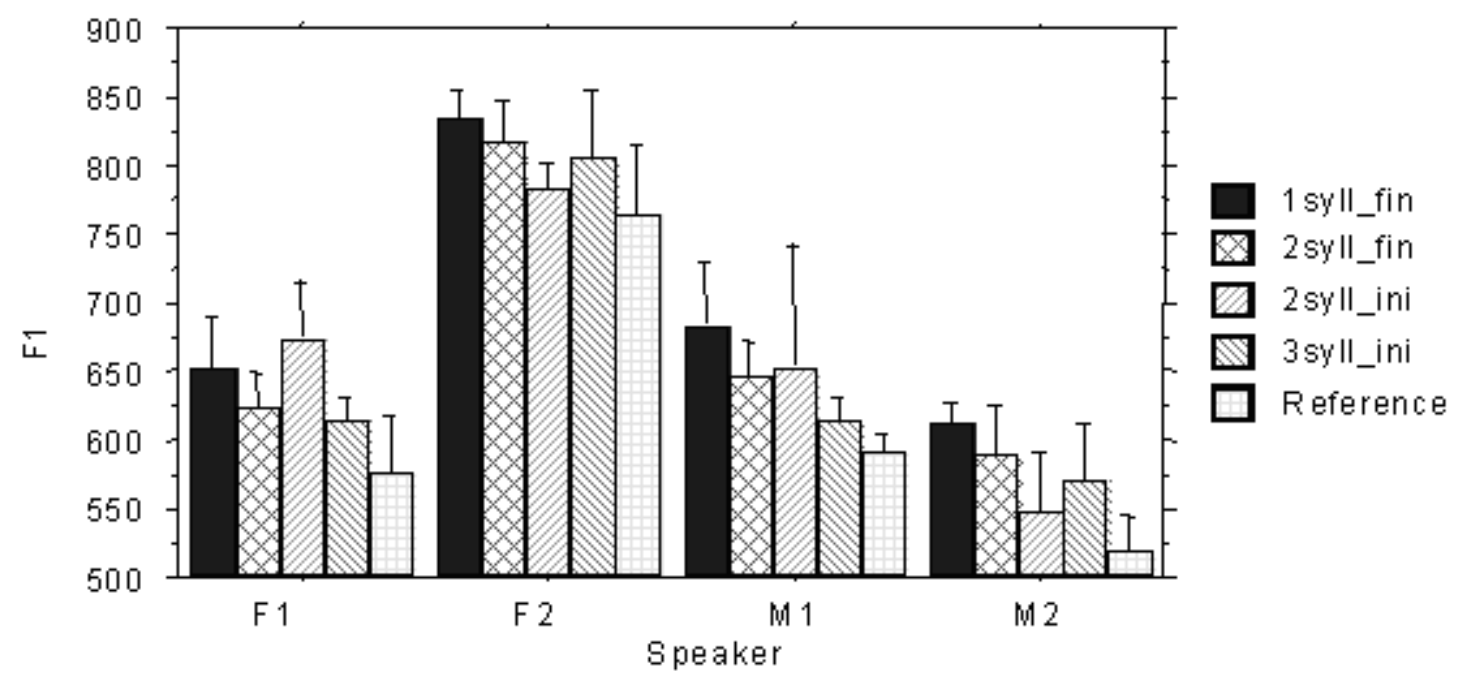

Figure 6: F1 values for /a/ for all speakers, comparing all conditions.

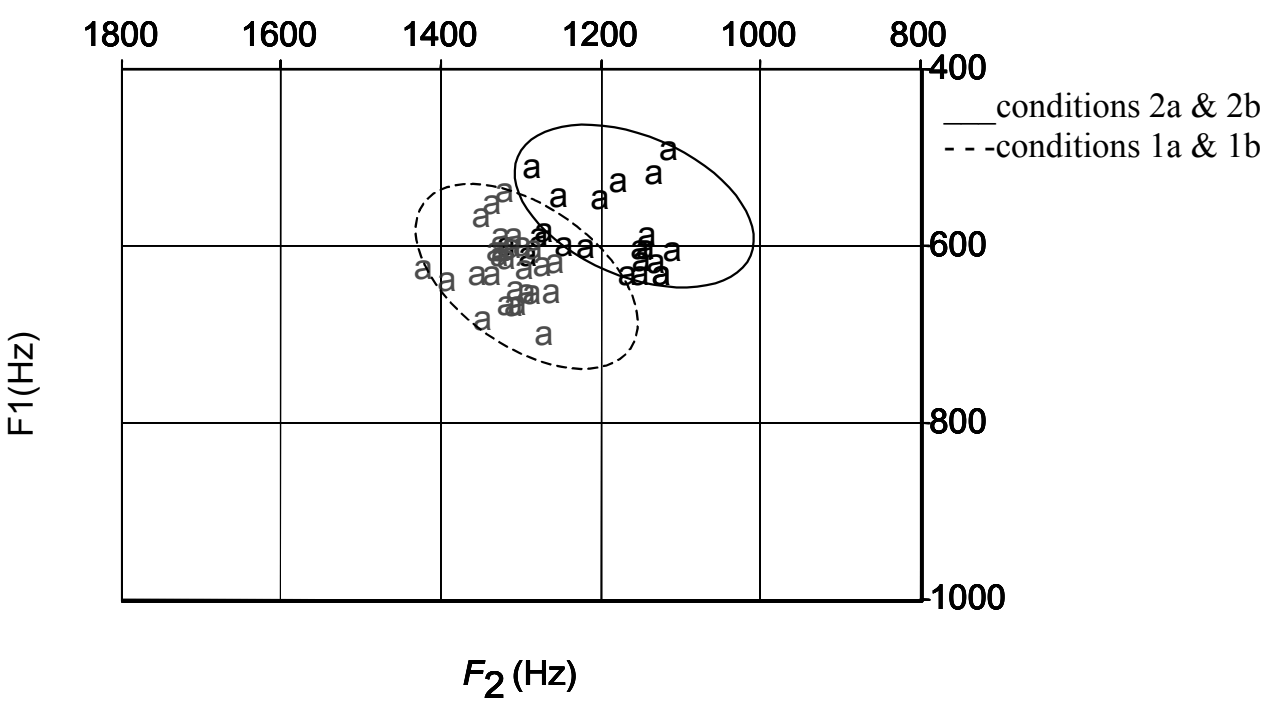

Figure 7: F1 and F2 values for /a/ for speakers M1 and M2, comparing vowels in word initial syllables (conditions $2 \mathrm{a} \& 2 \mathrm{~b}$ ) and vowels in word final syllables (conditions 1a \& 1b).

\subsection{Intra-Oral Pressure (PIO) measurements}

We expected no significant variations of PIO according to the different conditions as an increase in PIO would reflect an emphasis on the analysed vowel. The overall tendency is for vowels in word initial syllables to show a slightly higher PIO than their counterparts in word final syllables. However no effect of boundary surrounding on PIO could be observed for speaker M1 
$([\mathrm{F}(4,59)=0.405, \mathrm{p}=0.805])$, speaker $\mathrm{M} 2([\mathrm{~F}(4,61)=2.54, \mathrm{p}=0.064])$ and speaker $\mathrm{F} 2([\mathrm{~F}(4,53)=1.34, \mathrm{p}=0.27])$. An exception can be noticed for speaker $\mathrm{F} 1$ $[\mathrm{F}(4,63)=5.28, \mathrm{p}=0.0011]$ who produced vowels in word final syllables with greater values (of PIO) than vowels in word initial syllables. We cannot provide a clear interpretation of the results for speaker F1 here. This still suggests that word initial positions (when not emphasised) are in most of the cases not produced with a significant increase or decrease in intra-oral pressure compared to their counterparts in word-final positions.

\subsection{Kinematic measurements}

Word final vowels are generally characterised by a greater lip aperture movement as can be seen in figure 8 and 9 . This is specifically consistent for /a/ and /i/. It is true for all speakers including speaker F1 whose duration and f0 values didn't show the same tendencies as the other speakers (cf. 3.1. and 3.2). The reference condition (condition 3) for /a/ and /i/ shows larger opening movements than the initial syllables conditions in many cases; however these differences are rarely significant. Once again we cannot claim that the $\pi$ gesture's activity has been altered by the presence of the lexical word boundary (reference), as it rarely significantly conveys a supplementary lip aperture compared to the vowel in condition 2a (2_syll_ini).

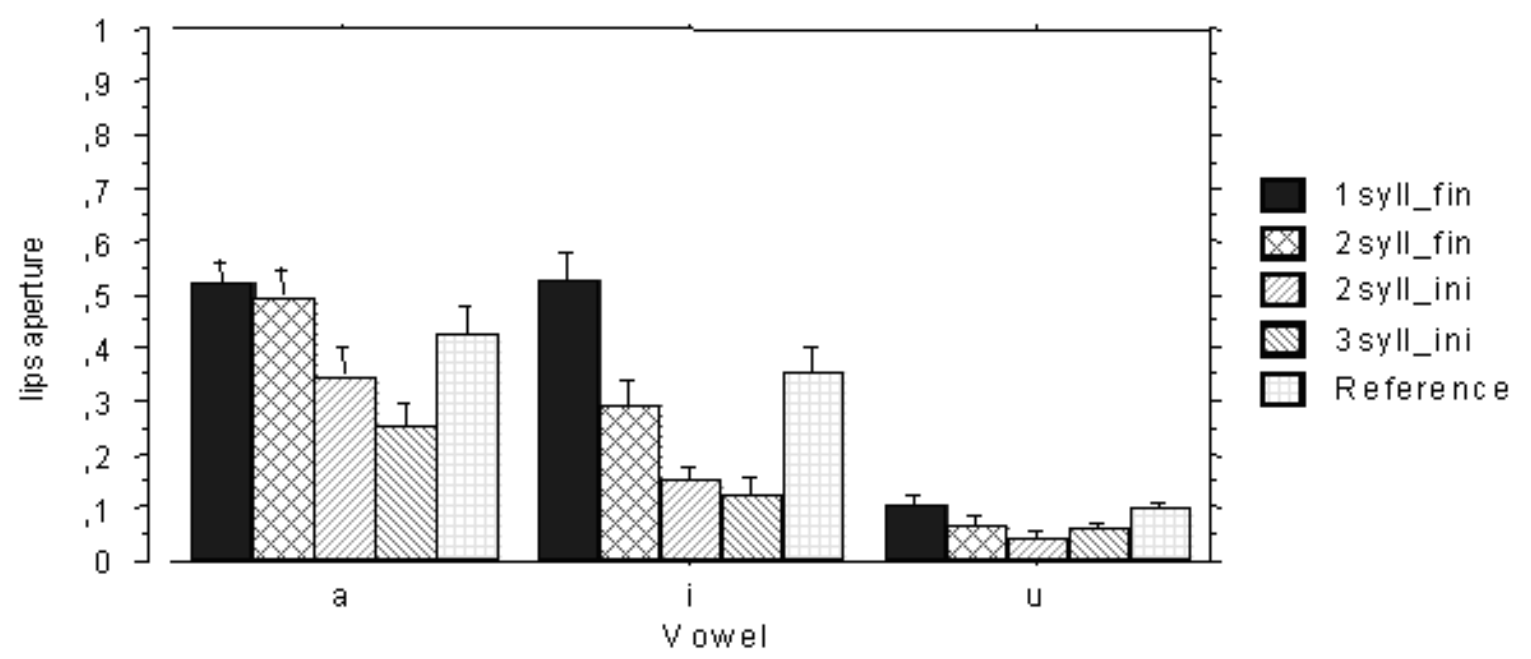

Figure 8: Lip aperture values for $/ \mathrm{a} /, / \mathrm{i} /$ and /u/ for speaker F1.

Following the idea that these temporal and spatial (lips movements) prosodic changes may not be interdependent (specifically for speaker F1), it would be interesting to investigate whether a spatial enlargement is possible without a 
temporal slowing down and vice versa: one way to evaluate this is to measure the velocity of the opening (and closing) gestures.

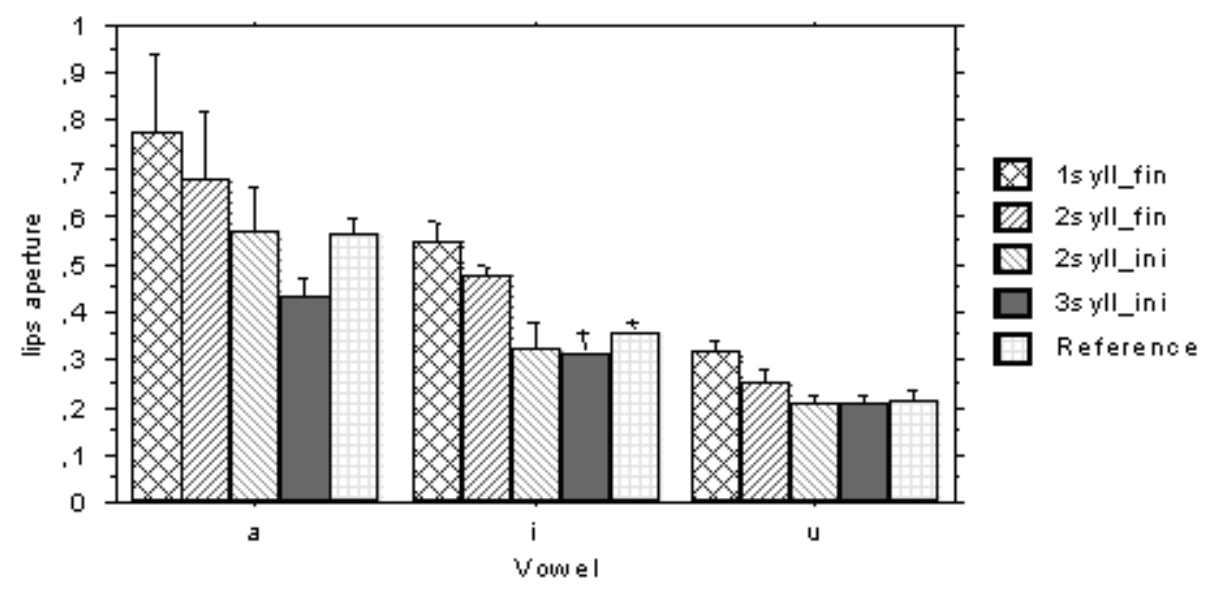

Figure 9: Lips aperture values for $/ \mathrm{a} /, / \mathrm{i} /$ and /u/ for speaker M1.

Maximum velocity was measured as the maximum value on the derivative of the lips' opening movements as found in the literature (Beckman \& Edwards 1992).

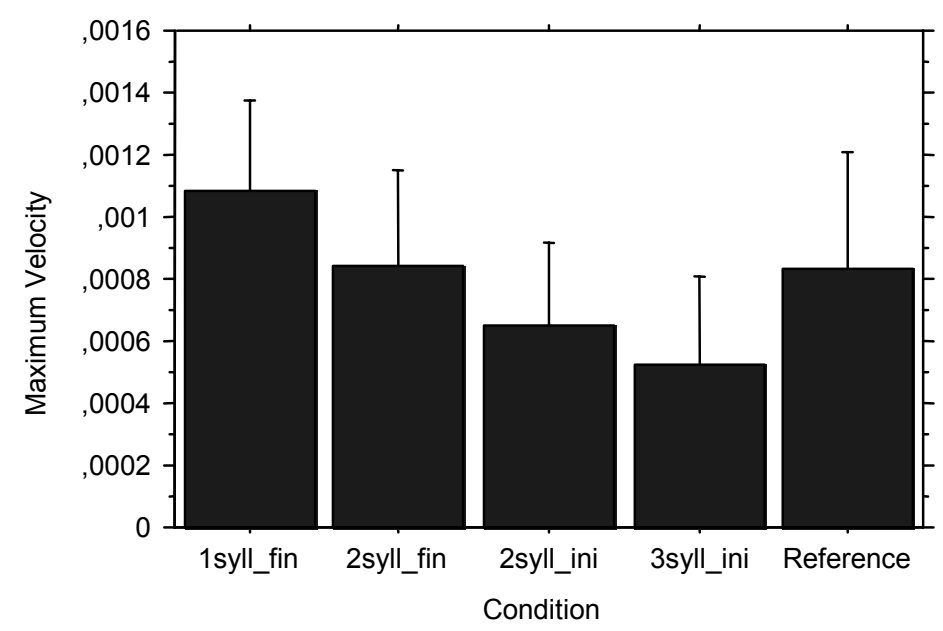

Figure 10: Maximum velocity values for $/ \mathrm{a} /$ for speaker F1.

The results for speaker F1 (cf. figure 10) indicate the same tendency as was found for duration for the other speakers. This suggests that the vowel /a/ in word final syllables is realised with a larger opening thanks to a higher maximum velocity while the duration of the vowel is not significantly higher. This configuration is different from other speakers for which temporal (longer vowels) and spatial (larger lip movements) changes seem to be interdependent. 


\section{Conclusion}

The $\pi$-gesture hypothesis seems to be confirmed in this experiment, i.e. vowels (in word final position) that are closer to the boundary are longer, have a higher f0, larger opening lips gestures. As shown for speaker F1, a higher maximum velocity during the vowel, still allowing the same gestural extent, may also compensate for a short duration, but this will have to be further investigated.

The results for the reference condition are coherent with the $\pi$-gesture hypothesis. The presence of the lexical word boundary (when compared to the condition 2a) generally conveys no significant extra lengthening and no larger lip opening gestures.

In our corpus we tested vowels in word initial syllables versus vowels in word final syllables; the word initial position is quite strong in French (as in several languages) and we know that it is a location for possible supra-glottic tension as mentioned by Vaissière (2004). The results for PIO indicate that vowels in word initial positions are not realised with a lower pressure compared to vowels in word final positions. However we found evidence for temporal reduction as well as for reduced lip aperture movements. The analysis of formant values suggested that vowels in word initial syllables could be considered as more coarticulated, rather than centralised. A complete investigation of the correlations between duration and gestural extent is needed to check whether a higher velocity in word-initial position may compensate for the temporal reduction.

\section{Acknowledgements}

My thanks to all at the Laboratoire de Phonétique et Phonologie, especially Jacqueline Vaissière, Shinji Maeda, Cécile Fougeron, Alexis Michaud. Preliminary findings were presented in 2004 at the German-French summerschool on Cognitive and physical models of speech production and perception and the production-perception interaction in Lubmin. Recordings were made at the "Hôpital Européen Georges Pompidou" with the help of Stéphane Hans. Many thanks for his useful hints and his obligingness. My deepest thanks to Jean Léo Léonard, Olivier Corbin, Céline Raynal and Frédérique Bénard for their patience during the recording sessions. Recording equipment was lent by the Laboratoire Phonétique et Phonologie-CNRS UMR7018, the École Doctorale 268 and the "Hôpital Européen Georges Pompidou". Finally the author would like to thank reviewers Christine Mooshammer and Bernd Pompino-Marschall for many helpful comments on this paper, as well as all the organisers of the German-French summerschool (...) for their tremendous work. 


\section{References}

Beckman, M. \& Edwards, J. (1992) Intonational categories and the articulatory control of duration. In: Y. Tohkura, E. Vatikiotis-Bateson, Y. Sagisaka (eds.), Speech Perception, Production, and Linguistic Structure. Tokyo: Ohmsha, Ltd. 359-375.

Benguerel, A. (1970) Some physiological aspects of stress in French. Ann Arbor: The university of Michigan, Phonetics Laboratory.

Boersma, P. \& Weenink, D. (1999) Praat, a system for doing phonetics by computer. Institute of Phonetic Sciences of the University of Amsterdam. 132-182.

Browman, C. \& Goldstein, L. (1992) Articulatory phonology: An overview. Phonetica, 49: 155-180.

Byrd, D. (2000) Articulatory vowel lengthening and coordination at phrasal junctures. Phonetica, 57: 3-16.

Byrd, D., Kaun, A., Narayanan, S. \& Saltzman, E. (2000) Phrasal signatures in articulation. In Michael B. Broe \& Janet B. Pierrehumbert (eds.) Papers in Laboratory Phonology V. Cambridge: Cambridge University Press. 70-87.

Byrd, D. \& Saltzman E. (2003) The elastic phrase: Modelling the dynamics of boundaryadjacent lengthening. Journal of Phonetics, 31: 149-180.

Cho,T. (2001) Effects of prosody on articulation in English PhD dissertation. University of California, Los Angeles. (Distributed as UCLA Dissertations in Linguistics, number 22).

de Jong, K.J. (1995) The supraglottal articulation of prominence in English. Journal of the Acoustical Society of America, 97: 491-504.

Di Cristo, A. (1998) Intonation in French, in Intonation Systems: A Survey of Twenty Languages, edited by D. Hirst and A. di Cristo (Cambridge University Press, Cambridge), pp. 195-212.

Delattre, P., Liberman, A., and Cooper, F. (1955) Acoustic loci and transitional cues for consonants. Journal of the Acoustical Society of America, 27(4).

Delattre, P. (1966) Studies in French and Comparative Phonetics, Mouton, La Haye.

Edwards, J., Beckman, M. and Fletcher, J. (1991) The articulatory kinematics of final lengthening. Journal of the Acoustical Society of America, 89(1): 369-382.

Erickson, D. (1998) Effects of contrastive emphasis on jaw opening. Phonetica, 55: 147-169.

Gendrot, C. \& Adda, M. (2004) Analyses formantiques automatiques de voyelles orales : évidence de la réduction vocalique en langues française et allemande. MIDL,Paris: 29-30.

Grammont, M. (1933) Traité de phonétique. Paris: Librairie Delagrave.

Harrington, J.; Fletcher, J.; Beckman, M. (2000). Manner and place conflicts in the articulation of accent in Australian English. In Beckman \& Kingston (eds.): Papers in Laboratory Phonology V: Acquisition and the Lexicon. Cambridge: University Press, 4051.

Hertegard, S., Gauffin, J. \& Lindestad, P. A. (1995) A comparison of subglottal and intraoral pressure measurements during phonation. Journal of Voice, 9(2):149-55. 
Jun, S.-A., \& C. Fougeron. (1997) A Phonological model of French intonation. Poster presented in the ESCA Workshop on Intonation, Athenes.

Keating, P., Cho, T., Fougeron, C., \& Hsu, C.S. (2003) Domain-initial strengthening in four languages. In J. Local, R. Ogden \& R. Temple (eds). Papers in Laboratory Phonology VI. Cambridge University Press. Cambridge, U.K.: 143-161.

Ladefoged, P. \& Draper, M. (1958) Syllables and Stress. Miscellanea Phonetica, 3: 1-14.

Lindblom, B. (1990) Explaining phonetic variation: a sketch of the H \& H theory. In Hardcastle, W. \& Marchal, A., eds., Speech production and speech modelling. Dordrecht. Kluwer: 403-440.

Lucci, V. (1983) Etude phonétique du français contemporain à travers la variation situationnelle. Grenoble: Publications de l'Université des Langues et Lettres de Grenoble.

Nooteboom, S.(1997) The prosody of speech: melody and rhythm. In: W. J. Hardcastle \& J. Laver (eds.), The Handbook of Phonetic Sciences, Basil Blackwell Limited, Oxford: 640673.

Pasdeloup, V. (1990) Modèles de règles rythmiques du fraçais appliqué à la synthèse de la parole. Thèse de Doctorat Nouveau régime, Université de Provence.

Recasens, D. (1999) Lingual coarticulation. In W. Hardcastle 1 N. Hewlett (eds), Coarticulation: theory, data and techniques, Cambridge University Press. Cambridge, U.K: 80-104.

Saltzman, E. \& Byrd, D. (2000a) Task-dynamics of gestural timing: Phase windows and multifrequency rhythms. Human Movement Science, 19(4): 499-526.

Saltzman, E \& Byrd, D (2000b) Demonstrating effects of parameter dynamics on gestural timing. Meeting of the Acoustical Society of America, Journal of the Acoustical Society of America, 107(5,2): 2904.

Straka, G. (1963) La division des sons du langage en voyelles et consonnes peut-elle être justifiée ? Travaux de Ling. et de Littérature, U. de Strasbourg, 2: 17-98.

Tabain, M. (2003a) Effects of prosodic boundary on /aC/ sequences: acoustic results. Journal of the Acoustical Society of America, 113(1): 516-531.

Tabain, M. (2003b) Effects of prosodic boundary on /aC/ sequences: articulatory results. Journal of the Acoustical Society of America, 113(5): 2834-2849.

Vaissiere, J. (1975) Une procédure de segmentation automatique de la parole en mots prosodiques, en Français. VIIiè mes Journées d'Etudes sur la parole, Nancy : 193-208

Vaissière, J. (2004) Perception of Intonation. In Handbook of Speech Perception, Blackwell, Oxford. 